\section{«Темные го Хулио Кортасара: от литературы к городСКИМ исследованиям}

\section{Алена Еременко}

В исследованиях города изучение литературы как источника не является чем-то новым. Так, известный британский писатель и культуролог Рэймонд Уильямс рассматривает роман Новейшего времени как средство изучения общества [Tambling, 2016]. Напротив, философ Вальтер Беньямин считал, что невозможно запечатлеть город в силу его многовековой истории (диахронный аспект) и разноликости (синхронный аспект) [Беньямин, 1996]. Идеолог ситуационизма Ги Дебор назвал город обществом спектакля, выделив в нем единственный процесс - потребление [Дебор, 1999]. Британский литературовед Джереми Тамблинг замечает проблематичность применения этой идеи к современному городу с его разрозненными социальными подразделениями и возросшей динамикой жизни. Он подчеркивает связь между «раздробленными группами» людей в городе и возрастающей "сложностью романов», которые в стремлении зафиксировать городскую реальность «отдаляют читателей от прежних форм познания» [Tambling, 2016, р. 2]. Тем не менее из специфического «натурализма» и документализма модернистской прозы берет свое начало как журналистика, с одной стороны, так и критическое изучение города - с другой, так что можно заключить: беньяминовский фланер с течением XX века превращается в урбаниста.

Сопоставляя многоликость города в рецепции первых «урбанистов», Тамблинг приходит к тому, что подвергает сомнению существование города как объективного явления, свободного от идеологических ассоциаций и манипуляций. Одним из документов, фиксирующих город как идеологический продукт, исследователь называет художественную литературу и, в частности, реалистический роман второй половины XIX века, в центре сюжета которого конфликт между растущим индустриальным городом и приходящим в упадок селом [Tambling, 2016, р. 24]. Литература, таким образом, видится как способ своего рода социологического исследования, поскольку последовательно отображает изнанку внешне наблюдаемых изменений. В такой литера турной перспективе реальный город рассыпается на индивидуальные перцепции фрагментов урбанистического полотна.
Еременко Алена Алексеевна, аспирантка Института филологии и истории Российского государственного гуманитарного университета; Российская Федерация, 125047, Москва, Миусская пл., д. 6, корп. 7, тел: +7 4952506540 E-mail: raduga_203@mail.ru

В статье обсуждается феномен города в художественной литературе. Цель автора-показать релевантность художественных текстов для городских исследований. Начиная с модернизма (1900-е годы), граница между фикциональностью (художественным вымыслом) и документалистикой нивелируется: автор стал хроникером, регистрирующим события без идеологической оценки. В тексте приводится обзор концепций, охватывающих город и литературу, от «протоурбанистов» (Беньямин, Дебор, Зиммель) до современных междисциплинарных подходов (городские культурные исследования, литературная и психогеография эконарратология). В центре внимания оказывается концепция темной экологии современного философа Тимоти Мортона. В темной экологии формулируется ранее не исследованная проблема: что происходит в пространстве без наблюдателя, то есть когда часть пространства остается в тени взгляда наблюдателя? В качестве модели для изучения этой проблематики в художественных текстах апробируется термин «темный город». Автор анализирует городские фрагменты в трех рассказах писателя-постмодерниста Хулио Кортасара, произведения которого относят к движению ситуационистов (художественная урбанистическая проза первой половины XX века). Рассказ «Записи в блокноте» тематизирует теневую сторону метрополитена. Создается образ метро как параллельного мира внутри города, что может быть прочитано как фантастический мир внутри мира действительности (фантастический жанр) или как манифестация теневой функции инфраструктуры. Рассказ «Граффити» иллюстрирует городскую субкультуру и через нее-городскую политику и коммуникацию. Фигура граффитиста выявляет потенциал очевидца «темной» повседневности в практиках визуализации (граффити) и вербализации (нарратив) коммуникации в городе. В рассказе «Газетные заметки» фиксируются пространства «дневного города» и «ночного города», различающиеся по влиянию на сюжет. Темнота стимулирует развитие своей непредсказуемостью и инаковостью, так что ночная прогулка по городу превращается в преступление. В заключение статьи предлагаются пути дальнейшего применения подхода темного города в малоизученных областях городских исследований: субкультурах, фольклоре и аффектах. 
Реакцией на размытость понятия пространства, которая обозначилась уже к середине XX века, стала работа Анри Лефевра «Производство пространства», в которой он выделил три формы мышления о пространстве: пространственная практика (spatial practice), репрезентация пространства (representations of space), пространство репрезентации (spaces of representation). Первое - о том, что совершают люди в пространстве; второе обозначает, как пространство отображено (картографировано); третье относится к тому, как пространство представлено для людей внутри него и как оно в конечном счете определяет их поведение [Лефевр, 2015].

По данной классификации город в художественной литературе является объектом комплексным. Будучи словесной репрезентацией фиктивного/реального пространства (в литературоведении для снятия проблемы соотношения реального и вымышленного употребляют термин «диегезис»-пространство разворачивающейся в произведении истории) и относясь ко второму типу мышления о пространстве по Лефевру, описанный город одновременно заявляет о себе через рефлексию персонажа или нарратора, что соответствует третьему типу пространства. Но литературный город имеет свойство «вторгаться» из текста в жизнь и влиять на восприятие города реального и даже на действия людей в пространстве, что задействует мышление первого типа. (Наиболее яркий пример - помимо булгаковской Москвы или Петербурга Достоевского - Блумсдэй (Bloomsday), праздник, ежегодно отмечающийся 16 июня в Дублине, Ирландия, во время которого сотни поклонников романа «Улисс» Джеймса Джойса проходят по городу маршрутом главного героя Леопольда Блума.). Итак, литературный город не существует обособленно в границах книги, но генерирует пространство извне. Это означает, что для изучения того, как город в жизни воспринимается человеком, помимо социологических и этнографических методов (интервью, опроса, ментальных карт и т. п.) могут в равной мере использоваться описания города в художественных текстах.

На тождестве реального и фикционального пространства основывает свои исследовательские практики литературная география, согласно которой все изображенные в литературе места образуют единую интертекстуальную карту, влияющую на перцепцию пространства реального [Saunders, 2010]. Другое направление междисциплинарных исследований, городские культурные исследования, исходят из того же положения: рефлексия о городе должна изучаться как в документальных, так и в художественных источниках, поскольку речь идет об антропологическом тождестве пространственной рефлексии. Городское пространство и материально, и виртуально одновременно: человек не в состоянии объять город во всей его количественной и качественной полноте. Большая часть пространства остается виртуальной для человека, что практически равноценно пространству воображаемому, «ненастоящему», фикциональному, литературному.

Оставаясь вне теории литературы, влияние пространства на текст долгое время сводилось к его репрезентации в качестве статичного фона для действий персонажей во времени. Особенно на такое положение дел повлияли работы Г.Э. Лессинга, разделившего искусства на статичные и динамичные [Лессинг, 1953]. Поворотным моментом для понятия литературного пространства стал XX век, когда стали обнаруживаться закономерности в репрезентациях пространства и времени в художественных произведениях разных эпох. Тогда же было изобретено понятие хронотопа [Бахтин, 1975]. Постепенно под влиянием феминистского, пространственного и когнитивного поворотов стали появляться работы, объединенные стремлением увидеть в художественных текстах механизмы перцепции пространства: значимые работы возникают в области исследований истории литературы [Moretti, 1998; 2005], нарратологии [Herman, 2001; Ryan et al., 2016],
Ключевые слова: город; литература; темная экология; темный город; Тимоти Мортон; Хулио Кортасар

Цитирование: Еременко А.А. (2021) «Темные города» Хулио Кортасара: от литературы к городским исследованиям//Городские исследования и практики. Т. 6. № 4. С. 47-55. DOI: https:// doi.org/10.17323/usp64202147-55 
геокритицизма [Westphal, 2011], гуманитарных исследований пространства (spatial humanities) [Tally, 2012; 2018], экокритицизма [Garrard, 2014] и эконарратологии [James, Morel, 2020].

Обилие направлений энвайронментального анализа напоминает ситуацию размытости теоретического концепта пространства в прошлом веке, о чем писал Лефевр. Последние два приведенных направления изучения художественных и не только текстов сосредоточены уже не на анализе описываемого пространства - тем более города, - а на выявлении и рефлексии глобальных экологических проблем. В этой связи корни «гео», «эко» и т.п. приобретают черты риторических фигур, полезная оболочка которых обнаруживает скрытый императивный акт. Контроль над экологическим состоянием служит реализации контроля геополитического и биополитического, что раскрыл Мишель Фуко в лекциях о государстве, территории и политике безопасности [Фуко, 2011]. Очевидно, что для того, чтобы исследования пространства реального или фикционального - были нейтральны по отношению к дискурсам власти, необходима переакцентуализация общеупотребительных понятий.

С нашей точки зрения, примером такой политически не маркированной операции является философская концепция темной экологии (dark ecology) Тимоти Мортона. Как проявление экологической озабоченности (ecological awareness), темная экология обозначает одновременное сосуществование множества форм жизни и протекания множества процессов, которые недоступны для перцепции человеком одномоментно и которые, соответственно, могут быть только осознаны [Morton, 2016]. В художественных текстах «темными» можно назвать любые пространства, если они не тематизируются в названии или в сюжете (примером тематизации могут служить произведения с названием города в заглавии или с сюжетом, напрямую связанным с городом, например «Берлин, Александерплац» А. Деблина, «Манхэттен» Д. Дос Пасоса, «Петербург» А. Белого и т.д.). Методом распознавания «темных» пространств служит степень их странности (weirdness) как для повествователя, так и для читателя [Morton, 2016, р. 6]. Таким образом, в поле анализа попадают скрытые ранее составляющие текста, которые, даже будучи неопознанными или неосмысленными, влияют на впечатление от истории и на саму историю, рассказанную в тексте.
Несмотря на поэтическую образность, понятие темного города представляет интерес в качестве альтернативной линзы для исследования городской жизни, причем существующей как объективно, так и субъективно - в художественных текстах. Как пишет Мортон, «тексты (включая формы жизни) говорят об их фундаментальной неразрешимости - неустранимой темной стороне» [Morton, 2016, р. 294]. Поскольку темная сторона сводится здесь к темным городам, представляется логичным задать вопрос: а какой он-темный город в литературе?

$$
\text { ** * }
$$

Произведения Хулио Кортасара', ярчайшего представителя литературного постмодернизма, автора как крупной, так и малой прозы, являются характерным случаем художественной фиксации городской жизни. При этом, хотя как таковая она не ставится в качестве творческой задачи, городская среда имплицитно присутствует в произведениях, оказывая экзогенное влияние на литературный нарратив. Для анализа были взяты три рассказа из сборника «Мы так любим Гленду» (Queremos tanto a Glenda, 1980): «Газетные заметки» (Recortes de prensa), «Записи в блокноте» (Texto en libreta) и «Граффити» (Graffiti). Во всех pacсказах события разворачиваются в городском пространстве, где герои становятся акторами городской жизни - но не повседневной, а «теневой», выходящей за рамки будничного восприятия горожанина. То, что происходит в транзитных местах, где человек пребывает недолго - например, в метро; и то, что происходит ночью, когда большинство людей спят.

Действие рассказа «Записи в блокноте» разворачивается в метро Буэнос-Айреса. Герой рассказа ведет записи своих наблюдений за людьми, которые никогда не поднимаются на поверхность земли. Этот с виду фантастический сюжет довольно органично встраивается в традицию изображения иных пространств в художественной литературе: начиная с мифических и ранних эпических сюжетов спуска в подземное царство Аида (Орфей в мифе об Орфее и Эвридике, Эней в «Энеиде») и заканчивая постапокалиптическими сюжетами выживания людей в метро (серия

\footnotetext{
1. На подготовку этой статьи автора вдохновила работа Полины Хановой, посвященная рецепции философии Тимоти Мортона через призму городских исследований [Ханова, 2019].
} 
книг «Метро 2044»). С точки зрения семиотики метро - это оппозиция пространству наземному - городу. Однако очевидна неполноценность этой оппозиции, а именно несопоставимость многообразия жизнедеятельности в наземном городе с утилитаризмом подземной части, суть которой заключается в транзитной функции. Но, как любая инфраструктура города, метро является и инструментом социального контроля и моделирования [Larkin, 2015], что очевидно в экспликации другой функции подземки - бомбоубежища. Исходя из терминологии Мортона, вторая функция метро является теневой и обычно не актуализируется в сознании горожанина.

В случае актуализации милитаристской функции метрополитена часть городской жизни переносится под землю, метро перестает быть только транзитным пространством и становится еще и обитаемым пространством как таковым. Можно сказать, что метрополитен имеет потенциал города "во второй степени»", и в рассказе Кортасара это становится особенно очевидным:

осторожные и все более частые погружения в метро, которое я теперь воспринимал как нечто совершенно другое, как чье-то медленное, отличное от жизни города дыхание, как пульс, который почему-то перестал биться для города, как нечто, переставшее быть только одним из видов городского транспорта [Кортасар, 2010, с. 55]. Чутье подсказывало мне, когда у меня еще хватало смелости спускаться и следить за ними, что большинство поездов полно ими, что обычных пассажиров становится все меньше и меньше; и я не удивляюсь, почему газеты кричат, что нужны новые линии, что поездов не хватает и надо принимать срочные меры [Кортасар, 2010, с. 74].

Так художественная литература актуализирует теневую функцию метрополитена как урбанистического пространства, что выходит за рамки городских исследований. В рассказе рисуется образ метро как параллельного мира внутри города, что может быть прочитано как фантастический

2. Если следовать филологическому понятию палимпсеста как "второй степени письма», введенному Жираром Женеттом для разграничения текстов первичных, матричных для литературы (Библия, «Одиссея», «Гамлет», «Дон Кихот») и вторичных, наслаивающих на матрицу новые обстоятельства и смыслы [Genette, 1982]. мир внутри мира действительности или как манифестация теневой функции инфраструктуры. Для городских исследований данный анализ может быть проведен на материале городского фольклора: баек, легенд, слухов - того, чем обычно пренебрегает урбанист в изучении городских пространств и сообществ. В частности, анализ городского фольклора может быть полезным инструментом для изучения такого психологического феномена, как тревога городского жителя, и других форм психологической аффектации.

Кортасар был не единственным писателем, поместившим столицу Аргентины в центр фантастического сюжета. Комиксантиутопия «Этернаут» (El Eternauta, 19571959) описывает Буэнос-Айрес, захваченный инопланетянами. Несмотря на явно фантастический характер что рассказа Кортасара, что комикса, исследователи склонны интерпретировать их сюжеты как рефлексию над политическими событиями в странах Латинской Америки 19501980-х годов (перонизм, военная хунта, политические репрессии и т. п.) [Ortega, 2016]. Автор комикса Эктор Эстерхельд и три его дочери исчезли в 1977 году и, скорее всего, были ликвидированы по распоряжению хунты. Близость политической и урбанистической сторон сюжетов показывает город как пространство контроля и власти. Так, Дэвид Харви замечает по поводу Парижа, что после трагедии Парижской коммуны 1848 года, которая привела к масштабной реконструкции столицы Франции для ликвидации условий для баррикад, город превратился в капитализированный проект, в диктаторский нарратив, в «тотальность» [Harvey, 2003].

В истории городских движений известен изначально литературный (сюрреалисты Анри Бретон, Луи Арагон и другие), а затем и политический кружок ситуационистов. После выхода романа Кортасара "Игра в классики» его стали считать близким по духу к этому кружку. Герои его романа блуждают по Парижу и стремятся пересечься, не договариваясь об этом заранее, ${ }^{3}$ - по описанию их действия напо-

3. Вон Андерсон замечает, что начало романа с фразы Encontraria la Maga? отсылает к сюрреалистическим произведениям Анри Бретона («Надя», 1928) и Луи Арагона («Парижский крестьянин», 1926), герои которых также заняты поисками женщин. Он также проводит параллель между представлением Парижа через призму музыки и темой ритма у Кортасара и Анри Лефевра, теоретика ситуационистов [Anderson, 2013]. 
минают ситуационистскую практику дрейфа-особого способа перемещения в городском пространстве как политического сопротивления [Kaufmann, 2006, р. 108-109]. В концептуальном поле ситуационистской прозы находится и рассказ Кортасара «Граффити»-как по названию, так и по занятию героя, делающего уличные рисунки, которые незамедлительно стирает полиция. В отличие от рассказа «Записки в блокноте», нам неизвестно название города - возможно, для недопущения прямых параллелей с реальными событиями. На авторское желание стереть политические коннотации указывает следующий фрагмент:

Ты просто развлекался, делая рисунки цветными мелками (тебе претил термин «граффити», слишком научный), и время от времени приходил посмотреть на них, тебе даже немного льстило, что это из-за тебя приезжала муниципальная машина и служащие стирали рисунки, ругаясь впустую. Им не важно было, что рисунки не политические, - запрещение касалось любых, и, если какой-нибудь ребенок осмеливался нарисовать дом или собаку, они все равно с оскорблением и угрозами стирали это. Обстановка в городе создалась такая, что уже неизвестно было, откуда ждать опасности: возможно, поэтому тебе и нравилось утверждать себя, делая рисунки, каждый раз подыскивая для этого подходящие время и место [Кортасар, 2010, с. 166].

В приведенном фрагменте проявляются психологические аспекты практики нанесения граффити на стенах городских улиц. Это не столько культурное явление, сколько явление социальное и даже психологическое, поскольку как знак граффити может выражать неотрефлексированные ощущения, связанные с окружающим пространством, - иначе оно не рисовалось в публичном месте. Так, исследователь постсоветской Варшавы отмечает, что городские граффити - потенциальный предмет исследования для memory studies как в локальных рамках, так и глобальных.

Краска на стене, по мнению исследователя, является знаком "свободного общественного пространства, освобожденного от влияния государства, которое когда-то сохраняло монополию на интерпретацию истории» [Pakier, Wawrzyniak, 2015, p. 3].
Кроме того, в приведенном фрагменте термин «граффити» назван "слишком научным» и поэтому не нравится герою - в действительности исторически термин graffiti использовался для описания дизайна поверхностей предметов, найденных в катакомбах Рима и Помпей ${ }^{4}$. Наивное замечание о термине маркирует его природу, «иную» по отношению к повседневной жизни. Ночь, когда, как правило, создаются граффити, чувство тревоги его автора, как и недолговечность рисунка, раскрывают первичную функцию граффити как сообщения - сначала между загробным миром и миром живых, затем между людьми, находящимися в одном физическом пространстве, но в разных семантических пространствах: социальных, политических, культурных. В состоянии города как внешнего детерминированного и подконтрольного мира граффити, как и другие виды городских художественных практик, является способом выражения запрещенной документальности, и при этом темным способом, поскольку граффити существует до утра, когда появляются «зачистные» службы:

еще до появления машин, которые убирали улицы, тебе открывалось пространство настолько чистое, что оно внушало надежду. Глядя издалека на свой рисунок, ты видел, как прохожие мельком смотрят на него, конечно, никто не задерживался, но никто и не проходил, не взглянув, - это могла быть наскоро сделанная абстрактная композиция в двух цветах, или контуры птицы, или две соединенные фигуры. Только один раз ты написал черным мелом фразу: "Мне тоже больно”.

Не прошло и двух часов, как полиция, на этот раз лично, заставила ее исчезнуть. После случившегося ты продолжал делать только рисунки [Кортасар, 2010, с. 166-167].

Факт короткой жизни граффити относит последний к манифестации темной стороны города, обнаружить которую можно, только зная ее язык:

Однажды вечером первый рисунок сделала она, ты увидел его: красными и голубыми мелками на воротах гаража, используя структуру изъеденного жучком дерева и шляпки гвоздей. В нем

4. Graffiti. Online Etymology Dictionary: https://www. etymonline.com/word/graffiti. 
была вся она - манера, краски, - но, кроме того, это была просьба или вопрос, способ обратиться к тебе [Кортаcap, 2010, c. 168].

Рассказ выявляет возможность стать очевидцем темной повседневности при встрече с практиками визуализации (граффити) и вербализации (нарратив) коммуникации в городе. Поэтому обращение внимания на граффити и другие формы street art не только как на городскую субкультуру, но и как на документ памяти и индивидуальной позиции может оказаться ключевым в понимании исследуемого городского пространства.

Проблема документальности эстетического явления актуальна для прозы Кортасара и входит в поле исследований, посвященных политике [Orloff, 2013],

постмодернизму [Juan-Navarro, 2000] и массмедиа [McCracken, 1977]. Последнее, "пространство массмедиа», часто изучается отстраненно от своего источника - города. По составляющим массмедиального пространства - кино, газеты, предметный мир как знаки культуры потребления можно обнаружить документальную прозу, оттененную фикциональным сюжетом. Теоретики географического пространства (такие, как Мишель Де Серто и Мишель Фуко) увидели в урбанистических текстах писателей-модернистов отражение не только внутренних переживаний, но и представлений о национальных и городских границах, политике и бессознательном. Так, исследовательница модернистской прозы Рэйчел Поттер акцентирует внимание на том, как в художественных текстах проявляются черты документа эпохи [Potter, 2012, р. 82]. Проводя параллель между развитием литературы и журналистики в начале XX века (в частности, анализируя эссе «Дух Лондона» Форда Мэдокса Форда (The Soul of London, 1905)), Поттер фиксирует стирание принципиальной границы между художественной и критической прозой. Литература, по ее словам, «создает гибридный текст, который документирует, а не вымышляет город, и отдает предпочтение личности рассказчика как источнику опыта и смысла» [Potter, 2012, р. 85]. Фикциональность и документалистика сливаются в модернистской литературе, одновременно меняется отношение к самой литературе. Автор перестает быть цензором мира, его взгляд-взгляд хроникера, регистрирующего события без идеологической оценки. С другой стороны, развитие техниче- ских средств фиксации и воспроизведения (фотографии, радио, кино) позволило литературе стать более экспериментальной и свободной в выражении восприятия мира, научило человека видеть истории повсюду, на каждой улице или площади, в каждом переулке 5 . В этом отношении по литературе как документу можно изучать современную социальную жизнь в городах, а также белые пятна или темные пространства, порой остающиеся на периферии или вне городских исследований.

Действие рассказа «Газетные вырезки» разворачивается на ночных улицах Парижа, где его главная героиня встречает девочку, отводит ее домой и становится свидетельницей, а затем участницей сцены насилия. В рассказе подчеркивается обстановка, спровоцировавшая эту встречу, ночной город с пустыми улицами, в котором повседневный ход жизни сменяется на некое иррациональное, диктуемое самой городской структурой движение:
Я <..> вышла на пустую и холодную улицу, на мой вкус слишком широкую для Парижа. <...> я так и не знаю, поче- му перешла на другую сторону, в этом не было никакой необходимости, по- скольку улица выходила на площадь Ля-Шапель, где я могла бы поймать такси; было безразлично, по какой сто- роне идти, я перешла просто так, про- сто потому, что у меня даже не было сил спросить себя, зачем я перехожу [Кортасар, 2010, с. 91].

В этом фрагменте заслуживает внимания момент, когда героиня переходит улицу. Он сопровождается фразами: «в этом не было никакой необходимости» и «было безразлично, по какой стороне идти, я перешла просто так». Оброненные как бы вскользь, фразы теряются в потоке нарратива. Усиленная повторами немотивированность этого перехода сообщает обратное - попытку зафиксировать поворотный для сюжета момент. Переход от одного события к другому в сюжете запараллелен переходу с одной стороны улицы на другую, что говорит о тесной связи между ходом повествования и перемещением в городе-иными словами, между творческим мышлением и пространственным.

При свете дня город-это привычное повседневное пространство, где передви-

5. «Но разве каждый уголок наших городов - не место происшествия? А каждый из прохожих - не участник происшествия?» [Беньямин, 2012, с. 129-130]. 
жения просчитаны и исход их предсказуем. При наступлении ночи повседневность прекращается, и пространство из предсказуемого и знакомого трансформируется в незнакомое и непредсказуемое. Примечательно, что героиня не может отыскать место ночной встречи с девочкой, потому что произойти такой переход может только ночью, в "темном пространстве», а не при свете дня:

Среди бела дня это ничуть не соответствовало моим воспоминаниям, и, хотя я двигалась, вглядывалась в каждый дом и перешла на другую сторону, как, помнится, сделала тогда, я не узнала ни одного подъезда, который походил бы на виденный мною в ту ночь, падавший свет скрывал все, словно бесконечная маска [Кортасар, 2010, с. 102].

Парадоксальным образом в рассказе фиксируются два пространства, которые можно определить как «дневной город» и «ночной город». Если первое, «светлое» пространство служит статичным фоном для разворачивающихся событий и не влияет на их ход, то второе, «темное» пространство, наоборот, активно воздействует на сюжет своей непредсказуемостью и инаковостью.

\section{$\star \star *$}

Концепция темной экологии, предложенная Тимоти Мортоном, обнаружила ранее не исследованную проблему - что происходит в пространстве, когда мы не смотрим на него, когда часть его остается вне нашего взгляда? Образ темного города служит моделью для изучения этой проблематики, а обращение к художественным текстам оправдывается неизбежностью репрезентации города как места действия. Наблюдения за "темными» городскими сюжетами, продемонстрированные в анализе трех рассказов, выявляют такие черты поэтики, как тревога и иной мир.

В одном из интервью Кортасар так формулирует свою тревогу о мире:

Я абсолютно убежден и с каждым днем ощущаю глубже и глубже: мы выбрали не тот путь, ошибочный путь. Короче говоря, человечество заблудилось, ошиблось дорогой... мы пустились по исторически неправильному пути, который ведет нас прямиком к финальной катастрофе, в любом случае нас ждет уничтожение-война, загрязнение окружающей среды, усталость, коллективное самоубийство, что угодно [Кортасар, 2001].

Думается, что это «мы» означает, прежде всего, жителей городов - тех, на ком лежит ответственность за будущее планеты.

И для обеспечения будущего следует быть внимательными к тому, что происходит вокруг, - как к явному, "светлому», так и к неявному, "темному».

\section{Источники}

Бахтин М. (1975) Формы времени и хронотопа в романе: Очерки по исторической поэтике//Бахтин М. Вопросы литературы и эстетики. М.: Художественная литература. С. 234407 .

Беньямин В. (1996) Париж, столица девятнадцатого столетия//Произведение искусства в эпоху его технической воспроизводимости. Избранные эссе. М.: Медиум. С. 142-163.

Беньямин В. (2012) Краткая история фотографии//Учение о подобии. Медиаэстетические произведения. М.: РГГУ. С. 129-130.

Дебор Г. (1999) 0бщество спектакля. М.: Логос. Кортасар Х. (2001). Беседы с Эвелин Пикон Гарфилд. Фрагменты книги//Иностранная литература. № 6. С. 177-203.

Кортасар Х. (2010) Мы так любим Гленду. М.: АСТ.

Лессинг Г. (1953) Лаокоон, или О границах живописи и поэзии//ЛессингГ. Избранные произведения. М.: Художественная литература. C. $385-516$.

Лефевр. А. (2015) Производство пространства. M.: Strelka Press.

Фуко М. (2011) Безопасность, территория, население. Курс лекций, прочитанных в Коллеж де Франс в 1977-1978 учебном году. СПб.: Наука.

Ханова П. (2019) Темные города: темная экология и Urban Studies//Логос. № 5 (132). C. $71-86$.

Anderson V. (2013) Unfrozen Music: Disrupted Synaesthesia in Julio Cortázar's Paris//Hispanic Journal. No. 1 (34). P. 115-129.

Garrard G. (ed.) (2014) The 0xford Handbook of Ecocriticism. 0xford: 0xford University Press.

Genette G. (1982) Palimpsestes, La Littérature au Second Degré. Paris: Éditions du Seuil.

Harvey D. (2003) Paris, Capital of Modernity. London: Routledge.

Herman D. (2001) Spatial Reference in Narrative Domains//Interdisciplinary Journal for the Study of Discourse. No. 21 (4). P. 515541 .

James E., Morel E. (eds.) (2020) Environment and Narrative: New Directions in Econarratology. Columbus: Ohio State University Press.

Juan-Navarro S. (2000) Archival Reflections: Postmodern Fiction of the Americas (Self-Reflexivity, Historical Revisionism, Utopia). Lewisburg, PA: Bucknell University Press. 
Kaufmann V. (2006) Guy Debord: Revolution in the Service of Poetry. Minneapolis: University of Minnesota Press.

Larkin B. (2013) The Politics and Poetics of Infrastructure//Annual Review of Anthropology. No. 42 (1). P. 327-343.

McCracken E.-M. (1977) The Mass Media and Latin American New Novel: Vicente Leñero and Julio Cortázar. University of California, San Diego.

Moretti F. (1998) Atlas of the European Novel, 1800-1900. London, New York: Verso.

Moretti F. (2005) Graphs, Maps, Trees: Abstract Models for a Literary History. London, New York: Verso.

Morton T. (2016) Dark Ecology: For a Logic of Future Coexistance. New York: Columbia University Press.

Orloff C. (2013) The Representation of the Political in Selected Writings of Julio Cortázar. Boydell \& Brewer Press.

Ortega T. (2016) 0esterheld y Cortázar: primer y último round por la revolución//Tebeosfera. Режим доступа: https://www.tebeosfera. com/documentos/oesterheld_y_cortazar_primer_y_ultimo_round_por_la_revolucion.html (дата обращения: 04.11 .2021$)$.

Pakier M., Wawrzyniak J. (2015) Introduction: Memory and Change in Eastern Europe: How Special?//Memory and Change in Europe: Eastern Perspectives. Studies in Contemporary European History. No. 16. P. 1-22. Berghahn Books.

Potter R. (2012) Modernism Literature. Edinburgh University Press.

Ryan M.-L. (2016) Narrating Space/Spatializing Narrative. Where Narrative Theory and Geography Meet. With Kenneth Foote and Maoz Azaryahu. Columbus: Ohio State University Press.

Saunders A. (2010) Literary Geography: Reforging the Connections//Progress in Human Geography. No. 34 (4). P. 436-452.

Tambling J. (ed.) (2016) Prologue: City-Theory and Writing, in Paris and Chicago: Space, Gender, Ethnicity. The Palgrave Handbook of Literature and the City. UK: Palgrave Macmillan. P. 1-22.

Tally R.T. (2012) Spatiality (The New Critical Idiom). London: Routledge.

Tally R.T. (2018) Topophrenia: Place, Narrative, and the Spatial Imagination (The Spatial Humanities). Bloomigton: Indiana University Press.

Westphal B. (2011) Geocriticism. Real and Fictional Spaces, New York: Palgrave Macmillan.
JULIO CORTÁZAR'S DARK CITIES: FROM LITERATURE TO URBAN STUDIES

Alena Eremenko, MA in Literature, PhD Student at Russian State University for the Humanities; 6 bldg., 7 Miusskaya sq. Moscow, 125047, Russian Federation, tel.: $+74952506540$

E-mail: raduga_203@mail.ru

Abstract. This article examines the phenomenon of the city in fiction, with the aim of demonstrating the relevance of fictional texts for urban studies. Beginning with modernism in the 1900s, it explores the border between fiction and documentary, and the development of the author as a chronicler who registers events without adding an ideological valuation. While giving an overview of the theories at the intersection of urban and literary studies, from the "proto-urbanism" of Benjamin, Debord, and Simmel to the modern interdisciplinary approaches of literary geography and econarratology, the article especially focuses on Timothy Morton's concept of "dark ecology". From this literature review emerges a previously unexplored problem: when a space is outside of any observer's gaze, does it remain stable, or does it change? Addressing this question, and building on Morton's work, I develop the term "dark city" for analyzing literary texts. Analogous to Morton's concept, the dark city determines unexplored realms of everyday city life, such as fears, emotions, or hidden control. To explore this concept, I analyze three short stories by Julio Cortazar, a situationist writer from the first half of the twentieth century. Cortazar's Text in a Notebook, as I argue, explicates the shadowy side of the metro. As a parallel world inside the city, Cortazar's image of the metro can be read either as a fantastical world inside the world of reality (sci-fi), or as a manifestation of the potential shadow functions of urban infrastructure. In another short story, Graffiti, he explores urban subcultures of communication, presenting the figure of the graffitist as an eyewitness to "dark" everyday urban life, both through his visual practice (graffiti) and his verbal practice (story). Finally, Cortazar's short story Press Clippings captures two spaces-the daytime city and the nighttime citywhich have different influences on the plot. Darkness stimulates the plot's development, I argue, because of its unpredictability and otherness, turning a night walk through the city into a crime. In the conclusion, the article proposes the further application of the term "dark city" to less-studied areas-specifically urban subcultures, folklore, and psychological effects.

Keywords: city; literature; dark ecology; dark city; Timothy Morton; Julio Cortázar Citation: Eremenko A. (2021) Julio Cortázar's Dark Cities: From Literature to Urban Studies. Urban Studies and Practices, vol. 6, no 4, pp. 47-55. (in Russian) DOI: https://doi. org/10.17323/usp64202147-55 


\section{References}

Anderson V. (2013) Unfrozen Music: Disrupted Synaesthesia in Julio Cortázar's Paris. Hispanic Journal, no 1 (34), pp. 115-129.

Bakhtin M. (1975) Formy vremeni i khronotopa v romane: Ocherki po istoricheskoi poetike [Forms of Time and Chronotope in the Novel: Essays on Historical Poetics]. Voprosy literatury $i$ estetiki [Questions of Literature and Aesthetics]. M.: Khudozhestvennaya literature [Moscow: Fiction Publishing House], pp. 234-407. (in Russian)

Benjamin V. (1996) Parizh, stolitsa devyatnadtsatogo stoletiya [Paris, Capital of the 19th Century]. Proizvedenie iskusstva $v$ epokhu ego tekhnicheskoi vosproizvodimosti. Izbrannye esse [The Work of Art in the Age of Mechanical Reproduction. Selected Essays]. M.: Medium, pp. 142-163. (in Russian)

Benjamin V. (2012) Kratkaya istoriya fotografii [A Short History of Photography]. Uchenie o podobii. Mediaesteticheskie proizvedeniya [The Doctrine of Similarity. Media-aesthetic works]. M.: RGGU, pp. 129-130. (in Russian)

Debord G. (1999) Obshchestvo spektaklya [Society of the Spectacle]. M.: Logos. (in Russian)

Cortazar Kh. (2001). Besedy S Evelin Pikon Garfild. Fragmenty knigi [in Conversation with Evelyn Picon Garfield. Fragments of the Book]. Inostrannaya literature [Foreign Literature], no 6, pp. 177-203. (in Russian)

Cortazar Kh. (2010) My tak lyubim Glendu [We Love Glenda So Much]. M.: AST. (in Russian)

Fuko M. (2011) Bezopasnost', territoriya, naselenie [Security, Territory, Population]. SPb.: Nauka [Saint Petersburg: Publishing House Nauka]. (in Russian)

Garrard G. (ed.) (2014) The 0xford Handbook of Ecocriticism. 0xford: 0xford University Press.

Genette G. (1982) Palimpsestes, La Littérature au Second Degré. Paris: Éditions du Seuil.

Harvey D. (2003) Paris, Capital of Modernity. London: Routledge.

Herman D. (2001) Spatial Reference in Narrative Domains. Interdisciplinary Journal for the Study of Discourse, no 21 (4), pp. 515-541.

James E., Morel E. (eds.) (2020) Environment and Narrative: New Directions in Econarratology. Columbus: Ohio State University Press.

Juan-Navarro S. (2000) Archival Reflections: Postmodern Fiction of the Americas (SelfReflexivity, Historical Revisionism, Utopia). Lewisburg, PA: Bucknell University Press.

Kaufmann V. (2006) Guy Debord: Revolution in the Service of Poetry. Minneapolis: University of Minnesota Press.

Khanova P. (2019) Temnye goroda: temnaya ekologiya i Urban Studies [Dark Cities: Dark Ecology and Urban Studies]. Logos [Logos] no 5 (132), pp. 71-86. (in Russian)

Larkin B. (2013) The Politics and Poetics of Infrastructure. Annual Review of Anthropology. no 42 (1), pp. 327-343.
Lessing G. (1953) Laokoon, ili o granitsakh zhivopisi i poezii [Laocoon: An Essay on the Limits of Painting and Poetry]. Lessing G. Izbrannye proizvedeniya [Selected Works]. M.: Khudozhestvennaya literature [M.: Fiction Publishing House], pp. 385-516. (in Russian)

Lefebvre A. (2015) Proizvodstvo prostranstva [Production of Space]. M.: Strelka Press. (in Russian)

McCracken E.-M. (1977) The Mass Media and Latin American New Novel: Vicente Leñero and Julio Cortázar. University of California, San Diego.

Moretti F. (1998) Atlas of the European Novel, 1800-1900. London, New York: Verso.

Moretti F. (2005) Graphs, Maps, Trees: Abstract Models for a Literary History. London, New York: Verso.

Morton T. (2016) Dark Ecology: For a Logic of Future Coexistance. New York: Columbia University Press.

Orloff C. (2013) The Representation of the Political in Selected Writings of Julio Cortázar. Boydell \& Brewer Press.

Ortega T. (2016) 0esterheld y Cortázar: primer y último round por la revolución// Tebeosfera. Available at: https://www.tebeosfera.com/documentos/oesterheld_y_cortazar_primer_y_ultimo_round_por_la_revolucion. html (accessed 04 November 2021).

Pakier M., Wawrzyniak J. (2015) Introduction: Memory and Change in Eastern Europe: How Special? Memory and Change in Europe: Eastern Perspectives. Studies in Contemporary European History, no. 16 pp. 1-22.

Potter R. (2012) Modernism Literature. Edinburgh University Press.

Ryan M.-L. (2016) Narrating Space/Spatializing Narrative. Where Narrative Theory and Geography Meet. With Kenneth Foote and Maoz Azaryahu. Columbus: Ohio State University Press.

Saunders A. (2010) Literary Geography: Reforging the Connections. Progress in Human Geography, no 34 (4), pp. 436-452.

Tambling J. (ed.) (2016) Prologue: City-Theory and Writing, in Paris and Chicago: Space, Gender, Ethnicity. The Palgrave Handbook of Literature and the City. UK: Palgrave Macmillan, pp. 1-22.

Tally R.T. (2012) Spatiality (The New Critical Idiom). London: Routledge.

Tally R.T. (2018) Topophrenia: Place, Narrative, and the Spatial Imagination (The Spatial Humanities). Bloomigton: Indiana University Press.

Westphal B. (2011) Geocriticism. Real and Fictional Spaces, New York: Palgrave Macmillan. 